\title{
Japan Aerospace Exploration Agency's public-health monitoring and analysis platform: A satellite-derived environmental information system supporting epidemiological study
}

\author{
Kei Oyoshi, ${ }^{1}$ Yosei Mizukami, ${ }^{1}$ Ryosuke Kakuda, ${ }^{2}$ Yusuke Kobayashi, ${ }^{2}$ Hiroki Kai, ${ }^{2}$ \\ Takeo Tadono ${ }^{1}$ \\ ${ }^{1}$ Earth Observation Research Center, Japan Aerospace Exploration Agency, Tsukuba, Ibaraki; \\ ${ }^{2}$ Remote Sensing Technology Center of Japan, Minato-ku, Tokyo, Japan
}

\begin{abstract}
Since the 1970s, Earth-observing satellites collect increasingly detailed environmental information on land cover, meteorological conditions, environmental variables and air pollutants. This information spans the entire globe and its acquisition plays an
\end{abstract}

Correspondence: Kei Oyoshi, Earth Observation Research Center, Japan Aerospace Exploration Agency, 2-1-1 Sengen, Tsukuba, Ibaraki 305-8505, Japan.

Tel.: +81.50.3362.7982 - Fax: +81.29.868.2961.

E-mail: ohyoshi.kei@jaxa.jp

Acknowledgments: the GlobCover land cover map was obtained from the ESA GlobCover 2009 Project. The administrative boundary data (vector format data) were obtained from the GADM database. MOD11C1 Collection-6 data were obtained from NASA's Land Processes Distributed Active Archive Center located at the USGS Earth Resources Observation and Science Center. Rainfall, shortwave radiation, soil moisture, NDVI, AOT, and altitude data were obtained from JAXA.

Key words: Earth-observing satellites; Infectious diseases; Environmental information; Online database; Geospatial data; JPMAP; JAXA.

Contributions: KO wrote the draft of manuscript and designed the study; YM and TT reviewed the multiple versions of manuscript and contributed on study design; RK, YK, and HK contributed on coding and data processing.

Conflict of interest: the authors declare no potential conflict of interest.

Funding: none.

Received for publication: 2 July 2018.

Revision received: 9 January 2019.

Accepted for publication: 12 January 2019.

CCopyright K. Oyoshi et al., 2019

Licensee PAGEPress, Italy

Geospatial Health 2019; 14:717

doi:10.4081/gh.2019.717

This article is distributed under the terms of the Creative Commons Attribution Noncommercial License (CC BY-NC 4.0) which permits any noncommercial use, distribution, and reproduction in any medium, provided the original author(s) and source are credited. important role in epidemiological analysis when in situ data are unavailable or spatially and/or temporally sparse. In this paper, we present the development of Japan Aerospace Exploration Agency's (JAXA) Public-health Monitoring and Analysis Platform available from JAXA, a user-friendly, web-based system providing environmental data on shortwave radiation, rainfall, soil moisture, the normalized difference vegetation index, aerosol optical thickness, land surface temperature and altitude. This system has been designed so that users should be able to download and utilize data without the need for additional data processing. The website allows interactive exchange and users can request data for a specific geographic location and time using the information gained for epidemiological analysis.

\section{Introduction}

Climate change affects human health in diverse ways, including direct impact from extreme weather, such as heat, drought and heavy rain, and indirect impact through natural systems, such as vector-borne, water-borne diseases and air pollution. Climate change also works through human systems exemplified by occupational strain, under-nutrition and mental stress. (Bowles et al., 2013; Smith et al., 2014). All these kinds of phenomena have emerged in various regions of the world threatening human civilization. It follows that the development of an understanding of climate-disease interactions, monitoring of outcomes and identification of opportunities for mitigating adverse effects are important public-health research issues (Altizer et al., 2013). The United Nations (UN) is well aware of such threats and has developed an agenda of Sustainable Development Goals (SDGs) tailored to meet these challenges. SDG no. 3 addresses infectious diseases and seeks to end epidemics caused by malaria, neglected tropical diseases and water-borne infections by the year 2030 aiming to ensure healthy lives and promote well-being for all at all ages (United Nations, 2018).

Infectious diseases occur as a consequence of close interaction between humans, animals and the environment they live in. Adopting the One Health approach, a collaborative effort of multiple disciplines to work for health across these three domains is essential for the identification of opportunities for health improvement and optimizing mitigation of risk (Lebov et al., 2017). Although estimates of the health impacts based on this approach require extensive data collection, information on important environmental variables are often missing or sparse with respect to both time and space. Insufficient data on parameters, such as tem- 
perature, rainfall, land use/land cover, atmospheric pollutants, forest fire and topography, prevent researchers and practitioners from conducting comprehensive investigations.

Earth-observing satellites (EOS) play a vital role in the collection of the above-mentioned environmental factors since they consistently observe the entire globe within rapidly repeated time periods. More than 30 years of archived data, used in epidemiological studies of infectious diseases, are currently available, including knowledge of air-pollution levels and extreme weather conditions related to communicable diseases, such as lung afflictions and heat stroke (Laaidi et al., 2012; Igarashi et al., 2014; Gebreslasie, 2015; Takane et al., 2016; Hasan et al., 2017). The Group on Earth Observations (GEO), the biggest community of this kind, uses satellite-generated in-situ observations to address areas of societal benefit, including public-health surveillance, aiming to provide alerts regarding air quality, weather extremes, water-related illness, vector-borne disease and assessments regarding access to health facilities.

As many governmental space agencies or enterprises have launched EOS, a wide variety of satellite-collected environmental data is currently available, and much of this knowledge is provided free of charge via the Internet. Available websites include the Copernicus open-access hub maintained by the European Space Agency (hscihub.copernicus.eu), the Land Processes Distributed Active Archive Center (LP DAAC) maintained by the United States (US) National Aeronautics and Space Administration (lpdaac.usgs.gov) and Geological Survey (USGS) and the Globe Portal system (G-Portal) provided by Japan Aerospace Exploration Agency (gportal.jaxa.jp/gpr). However, to make use of the data downloaded from these sites, additional data processing is generally needed for the desired epidemiological analyses to be carried out. For example, to acquire annual daily rainfall data for a specific area, 365 scenes must first be downloaded, then a subset of areal data must be generated and used to calculate the average rainfall. Further, to acquire surface temperature data in addition to rainfall data, a separate dataset must be downloaded and it may have a different data format since surface temperature and rainfall are retrieved from different sensors onboard different satellites. The risk of this problem not only increases when data are retrieved from different websites, but it can also prevent researchers from utilizing satellite-derived environmental information properly.

Satellite agencies have made much effort to develop satellitebased environmental information including climatic factors, biophysical parameters, topographic data, etc. The values of these variables have been validated with ground-based measurements to ensure accuracy (e.g. Wan, 2014; Oliveira et al., 2016; Colston et al., 2018), and they may also have been subjected to inter-comparison of satellite-based measurements from different sensors to refine them (e.g. Li et al., 2014). In addition, satellite products are translated into input parameters, e.g., using the numerical crop model (Sakai et al., 2015). However, there are advantages and disadvantages with each product and users have to select the products to meet their specific needs carefully, which would be similar to select reanalysis climate data provided by various agencies (Ceglar et al., 2017). We have selected and integrated some validated environmental information distributed via different websites with different formats to construct a new web-based database. Our goal was to develop a user-friendly online system providing satellitederived environmental information for the purposes of epidemiological analysis. The system presented here enables users to search, visualize, and download data that have been spatio-temporally preprocessed so that the data can be utilized immediately after download without additional processing.

\section{Materials and Methods}

\section{Overview}

Figure 1 shows an overview of JAXA's Public-health Monitor and Analysis Platform (JPMAP) (JAXA, 2018), developed to provide satellite-derived environmental information, including shortwave radiation (solar radiation with wavelengths between $300 \mathrm{~nm}$ and $4 \mu \mathrm{m}$ ), rainfall, soil moisture, normalized difference vegetation index (NDVI), aerosol optical thickness (AOT), land surface temperature (LST), and altitude (Table 1), primarily to epidemiologists. The majority of this satellite-generated information comes from the JAXA Satellite Monitoring for Environmental Studies (JASMES) (JAXA, 2013), which provides a wide variety of physical variables retrieved from NASA's moderate resolution imaging spectroradiometer (MODIS) onboard the Terra and Aqua satellites. MODIS and the data it provides was used as the basis for the development of similar physical variables from the SecondGeneration Land Imager (SEGLI) onboard the Global Change Observation Mission-Climate (GCOM-C) satellite launched by JAXA on December 23, 2017 (JAXA, 2017). SGLI has a finer spatial resolution than MODIS in the visible to thermal infrared bands with every two days observation (Okamura et al., 2018) and will eventually replace the MODIS as data source for JASMES providing the GCOM-C products instead.

All data are acquired at repeat times ranging from hourly to

Table 1. Sources of environmental data used on Japan Aerospace Exploration Agency's Public-health Monitoring and Analysis Platform.

\begin{tabular}{|c|c|c|c|c|}
\hline Product & Units & Grid size & Data interval & Data source \\
\hline Rainfall & $\mathrm{mm}$ & $10 \mathrm{~km}$ & Hourly & JAXA \\
\hline Shortwave radiation & $\mathrm{W} / \mathrm{m}^{2}$ & $5 \mathrm{~km}$ & Daily & JAXA \\
\hline LST & ${ }^{\circ} \mathrm{C}$ & $5 \mathrm{~km}$ & 4 times/day & NASA/USGS \\
\hline AOT (at $550 \mathrm{~nm}$ ) & Unit-less & $5 \mathrm{~km}$ & Daily & JAXA \\
\hline NDVI & Unit-less & $5 \mathrm{~km}$ & Daily & JAXA \\
\hline Soil moisture content & Volume\% & $25 \mathrm{~km}$ & Every 2 days & JAXA \\
\hline Altitude & $\mathrm{m}$ & $30 \mathrm{~m}$ & - & JAXA \\
\hline
\end{tabular}

JAXA, Japan Aerospace Exploration Agency; LST, Land surface temperature; NASA/USGS, National Aeronautics and Space Administration/United States Geological Survey; AOT, Aerosol Optical Thickness; NDVI, Normalized Difference Vegetation Index. 
every other day, except the altitude information, which is displayed only when users select a point reference in the geographic region studied, as a spatial average of the altitude would be useless. The JPMAP archive currently covers the period from 2002 to 2016.

\section{Available datasets}

JPMAP utilizes JASMES products including shortwave radiation (Frouin and Murakami, 2007; Saigusa et al., 2010) and NDVI, which indicates the amount of green leaf area or green leaf biomass whereby dense vegetation gives a high NDVI value (Tucker, 1979) capable of capturing the vegetation phenology by time-series, and AOT acquired through the attenuation of light at the $550 \mathrm{~nm}$ wavelength between the ground and the top of the atmosphere, which is closely related to the amount of aerosols in the atmosphere (Fukuda et al., 2013). The LST data used in the JPMAP system comes from the MODIS LST product MOD11C1 Collection-6 algorithm, obtained from the NASA/USGS site (https://e4ft101.cr.usgs.gov) and processed according to Wan (2014). Four daily LST values observed at 1:30, 10:30, 13:30, and 22:30 (local times) are available and JPMAP utilizes all four. The soil moisture content data were obtained from the G-Portal mentioned above. These data are generated by the Advanced Microwave Scanning Radiometer (AMSR-E) onboard the US Aqua satellite and the AMSR2 onboard the Japanese GCOM-W satellite (Fujii et al., 2009). However, soil moisture content data from November 2011 to June 2012 are unavailable due to an operational gap between the AMSR-E and AMSR2 at this time. The Global Satellite Mapping of Precipitation (GSMaP) product (Figure 2), obtained from JAXA (JAXA, 2007), is used for the rainfall data. This represents hourly global rainfall data covering the area between the latitudes 60 South and 60 North retrieved from EOS data (Kubota et al., 2007). For altitude data, JPMAP uses the Advanced Land Observing Satellite World 3D-30 m (ALOS AW3D30) (JAXA, 2015). The AW3D30 was developed using multi-angle (nadir, forward and backward) observational data from the Panchromatic Remote-sensing Instrument for Stereo Mapping (PRISM) onboard ALOS, a satellite launched in January 2006 completing its mission in May 2011 (Tadono et al., 2014). The AW3D30 was developed using the ALOS PRISM data acquired during this period.

\section{System architecture}

Apart from the structural design shown in Figure 1, the data provided by JPMAP are obtained from different websites or file transfer protocols (FTP), a standard used for transfer of computer files between servers and clients. In order to improve data accessibility for epidemiological studies, JPMAP not only collects these datasets, but also pre-processes them before distribution. Searched results are displayed both graphically (time-series chart) and in text. Time-series and spatial processing are performed on the sys-

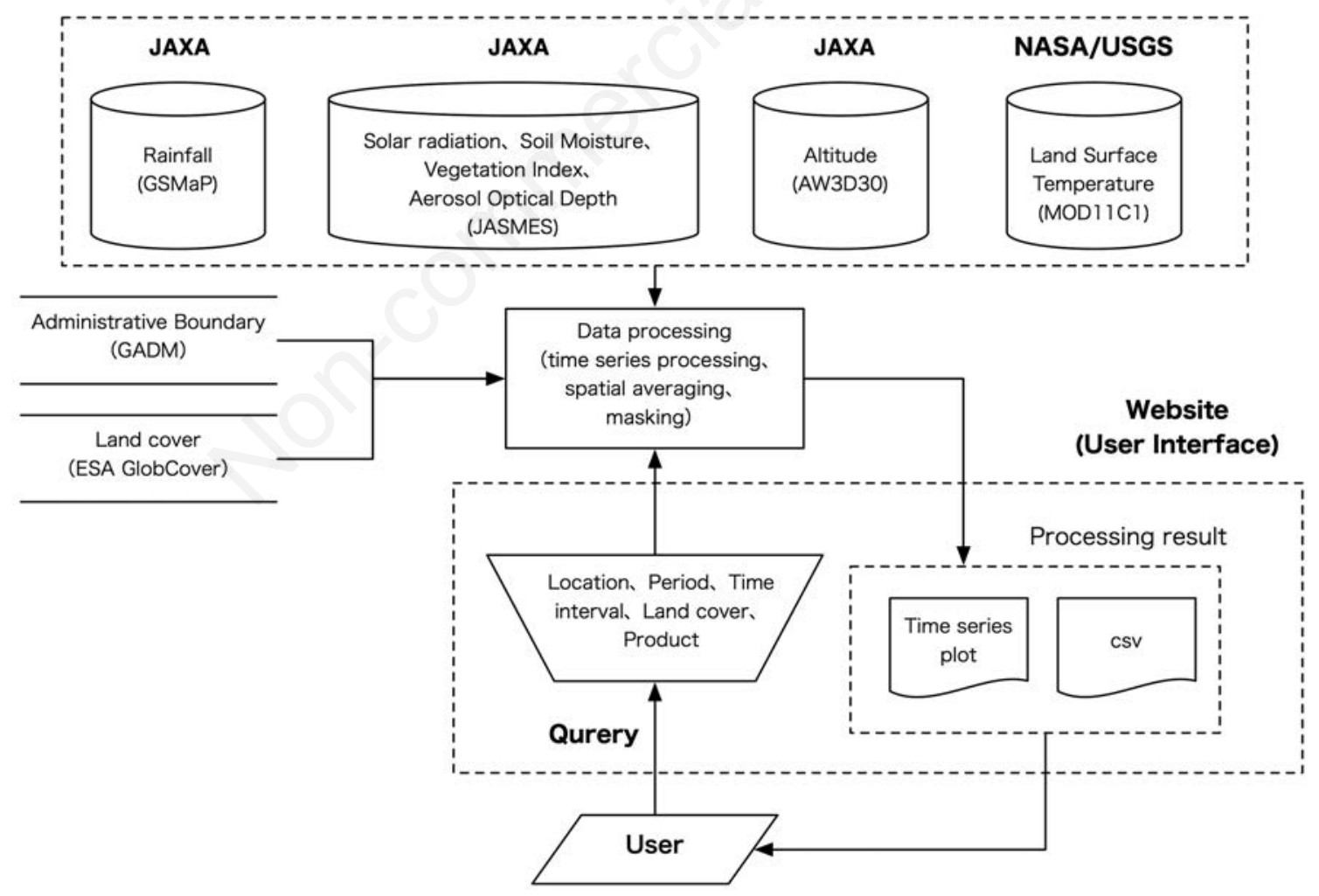

Figure 1. Overview of the satellite-derived environmental information provision system (JPMAP). JPMAP users can send queries to the system via the JPMAP website user interface, which results in spatio-temporal processing of archived data. Users can also generate timeseries plots based on query results and download time-series data. JAXA, Japan Aerospace Exploration Agency; NASA/USGS, National Aeronautics and Space Administration/United States Geological Survey; GSMap, Global Satellite Mapping of Precipitation; JASMES, Satellite Monitoring for Environmental Studies; AW3D30, Advanced Land Observing Satellite World 3D-30; GADM, Global Administrative Areas database. 
tem interactively based on user queries so that the datasets can be accessed without need for additional processing by the user.

All the satellite-derived environmental information mentioned above is converted to the Network Common Data Form (NetCDF) format and stored on the JPMAP web server. In response to user queries, the system performs spatio-temporal processing of archived data and presents a time-series plot of the results asked for. Spatio-temporal data processing, visualization of searched results and conversion of these data to the comma-separated value (CSV) format are executed in response to user queries at the website. However, user registration is required for downloading of CSV data. The website and the interactive processing is done using hypertext markup language (HTML) and Python.

Spatial averages are calculated when users select rectangles or administrative boundaries for the geographic regions they are interested in. The spatial average of a specific land cover within the selected rectangle, or administrative boundary, is also calculated when users select a specific land cover as extra option. JPMAP calculates this spatial average by averaging the pixels within, and intersecting with, the selected boundary. Temporal processing is performed when users select daily, half-monthly or monthly data intervals to get representative values within the specific area chosen. Accumulation is calculated for rainfall, average for shortwave radiation, soil moisture, AOT and LST, while the maximum value within the period is given for NDVI selections.

As ancillary data, the administrative boundary and land cover data are used to calculate the spatial average. The administrative boundary data (vector format data) were obtained from the Global Administrative Areas database (GADM, 2018), and land cover data with a spatial resolution of $300 \mathrm{~m}$ are obtained from ESA GlobCover (Bontemps et al., 2011).

\section{Graphical user interface}

Figure $3 \mathrm{~A}$ shows a screenshot of the graphical user interface
(GUI) of the JPMAP system. Users can make the following selections: geographic region (point, box or boundary), time period (start and end), interval (daily, half-monthly, or monthly) and product (shortwave radiation, LST, AOT, NDVI, rainfall or soil moisture content. In addition to these selected products, altitude is displayed automatically, but only when users select a point reference in the geographic region studied, while land cover can be selected as an extra option. When the user selects a box or boundary as the geographic parameter, JPMAP calculates the spatial average of the selected land cover within that region.

An example of a search query result is shown in Figure 3B for the time-series changes of a selected variable. Figure $3 \mathrm{C}$ shows the search query result with CSV data. The query result of CSV data for which a box or boundary was selected as the geographic region contains the numbers of total and valid pixels within the selected region and the standard deviation of the valid pixels. The numbers of total and valid pixels in an area occasionally differ if there are missing values, mainly due to cloud cover or an inherent observation schedule.

\section{Examples of search query results}

JPMAP covers almost the entire globe and users may submit queries to be utilized for epidemiological analyses regarding environmental factor(s) related to specific period(s) and location(s). Figure 4 shows examples of query results regarding specific geographical points (latitude and longitude), e.g., a monthly timeseries chart of rainfall around Dhaka, Bangladesh (N 23.823, E 90.414) from 2010 to 2016 (Figure 4A), or a monthly time-series chart of the NDVI in a cropland around Kisum, Kenya (S0.122, E34.293) from 2010 to 2016 (Figure 4B). Rainy seasons are clearly identified as beginning in April or May, and annual variations can also be identified in the first example, while double-cropping is investigated in the second. The latter is strongly related to the NDVI according to the vegetation density. Rain-fed croplands are

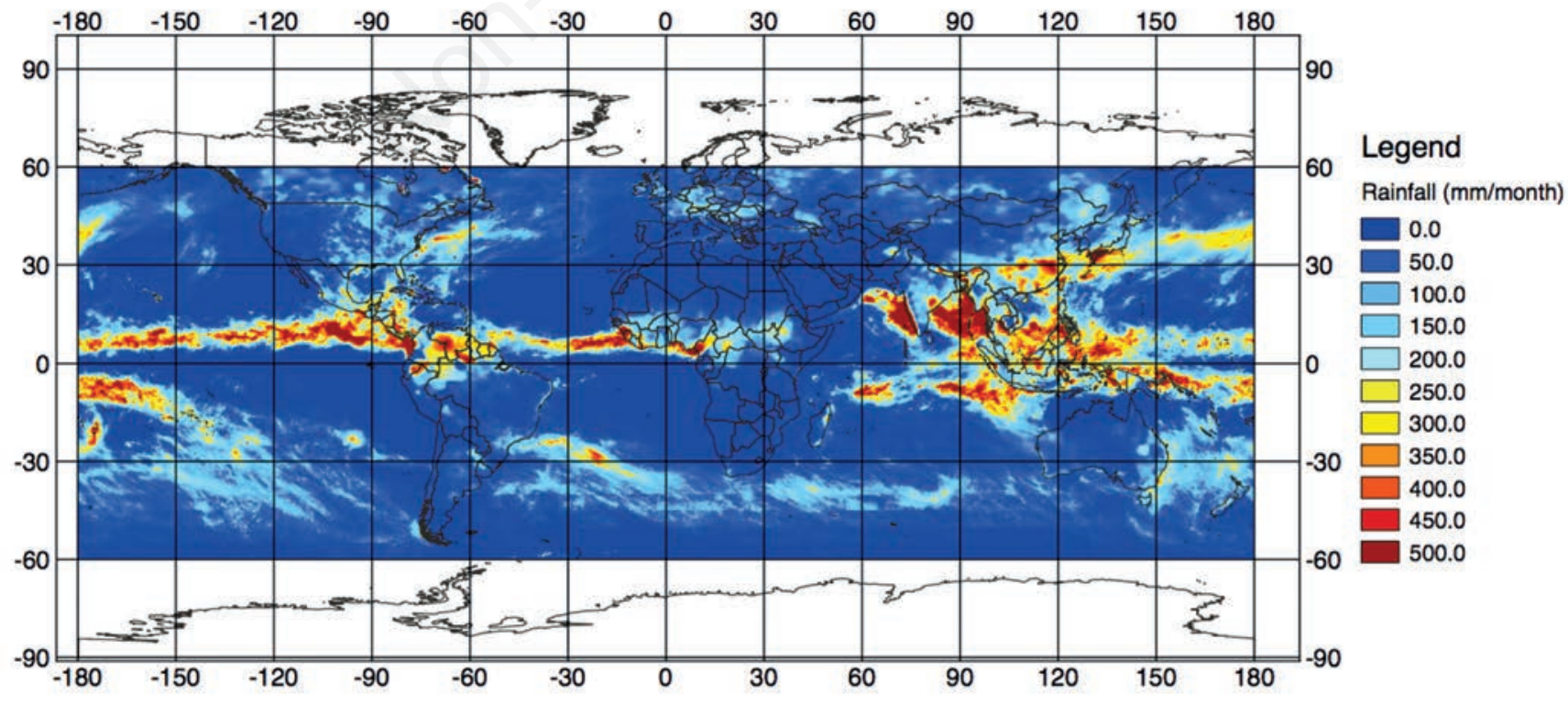

Figure 2. Satellite-derived monthly rainfall data (GSMaP) for June 2016. 
A Jaxa's Public-health Monitor and Analysis Platform Top | Overview | Users Guide | Links | English | Japanese Search Environmental Information Derived from Earth Observation Satellites
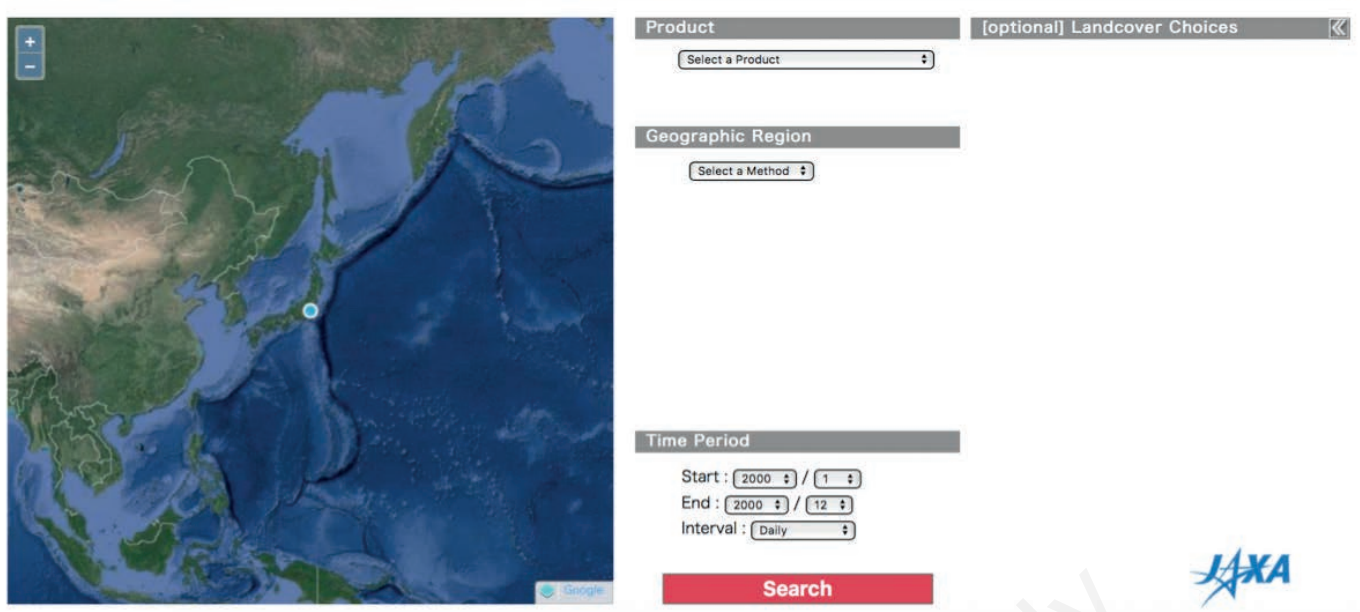

B

Jaxa's Public-health Monitor and Analysis Platform

Top | Overview | Users Guide | Links | English | Japanese
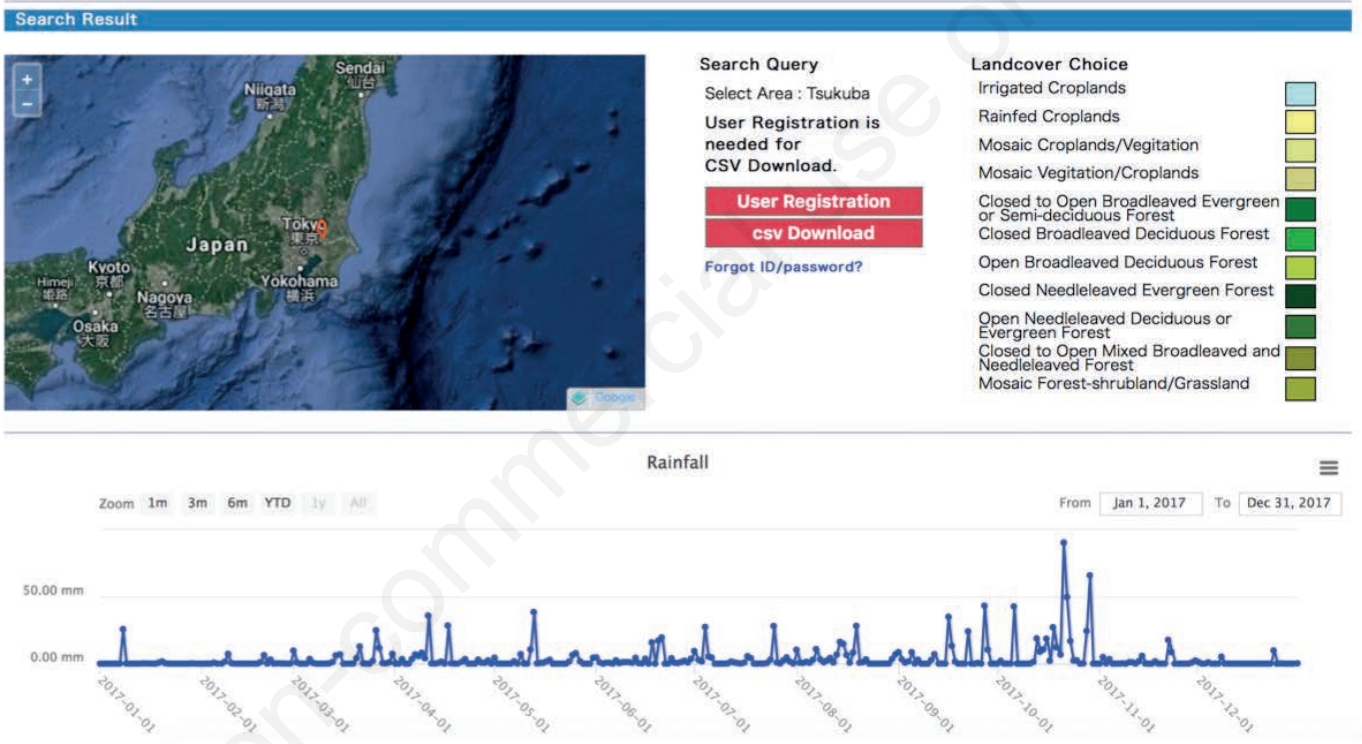

C date, average,standard_deviation,total_pixel,valid_pixel

2016-01-01,0.0173,0.0064,8,8

2016-01-02,0.0000,0.0000,8,8

2016-01-03,0.0000,0.0000,8,8

2016-01-04,0.0000,0.0000,8,8

2016-01-05,0.0000,0.0000,8,8

2016-01-06,0.0000,0.0000,8,8

2016-01-07,0.0000,0.0000,8,8

2016-01-08,0.0000,0.0000,8,8

2016-01-09,0.0001,0.0002,8,8

2016-01-10,0.0001,0.0002,8,8

2016-01-11,0.2755,0.1345,8,8

2016-01-12,0.2755,0.1345,8,8

2016-01-13,0.0000,0.0000,8,8

2016-01-14,0.0000,0.0000,8,8

2016-01-15,0.0000,0.0000,8,8

2016-01-16,0.0000,0.0000,8,8

2016-01-17,31.3147,3.8634,8,8

2016-01-18,15.5153,3.2171,8,8

2016-01-19,0.1149,0.0730,8,8

2016-01-20,0.0273,0.0113,8,8

2016-01-21,0.0000,0.0000,8,8

2016-01-22,0.3985,0.1110,8,8

Figure 3. Graphical user interface of online environmental data provision system. (A) Top Page; (B) Search query result (time-series chart); (C) Search query result (CSV format). 
highly vulnerable to rainfall shortages, as compared to irrigated croplands that enjoy adequate water resources. In addition, a decrease in the harvest can be identified by a low NDVI anomalous compared to that of a normal year. The NDVI captures not only the cropland phenology shown here, but also the existence and phenology of other types of land cover, such as grassland, forest, and wetlands. This range of environmental information about vegetation conditions is commonly used in the study of disease vectors.

\section{Results and Discussion}

We present here JPMAP, an online environmental information provision system, which collects, stores and integrates satellitederived environmental information distributed by different web or FTP sites, which users can search, visualize and download. Although there are several sources of satellite data that are openaccess and free to the public, primarily from governmental agencies such as NASA, ESA and JAXA, it can be difficult for general users to utilize these data because they require expertise in remote sensing or image processing. Such expertise is not needed as JPMAP users can utilize the satellite-derived environmental information for epidemiological analyses directly. As many authors have reported, environmental information is closely related to the occurrence of epidemiological diseases (e.g., Beck et al., 2000, Altizer et al., 2013). The environmental information provided by JPMAP, which covers almost the entire globe on a daily basis (for soil moisture every other day), is very useful for investigating the relationships between environmental factors and disease, in most cases by considering effects influencing the vectors of these diseases.
JPMAP has, however, some limitations, i.e. parameters such as LST, NDVI, and AOT are unavailable when the target area is overcast, which is an inherent limitation of remote sensing relying on optical sensors. Spatial resolutions can range from 5 to $25 \mathrm{~km}$, which means that their data footprints differ, a fact that must also be considered when using data from various providers and websites. In order to utilize the system effectively, users must understand and take such issues into account. In addition, some datasets are spatially aggregated to a coarser spatial resolution than their original forms due to limitations in data storage and data processing speed.

JPMAP provides seven types of environmental information, but other useful environmental information can also be retrieved from satellite data, such as the cloud cover ratio, wild fire, leaf area index, water surface chlorophyll-a (a specific form of chlorophyll used in oxygenic photosynthesis), water inundation or snow cover. Some of these parameters may be added to JPMAP based on user feedback. Furthermore, although JPMAP currently covers the period from 2002 to 2016, we plan to add more recent data and functions to update acquired data in near-real time in the near future, which would make the development of early warning systems for diseases possible through interdisciplinary collaboration between epidemiologists working with remotely sensed data. Ten-minute interval data are currently available at multi-spectral bands ranging from the visible to thermal infrared bands, as observed by geostationary satellites (Bessho et al., 2016). These data will prove useful information for early warning systems given that very high-frequency data provide observations almost in real time. In addition, huge volumes of satellite-derived information could be useful for input in the field of artificial intelligence techniques based on machine learning currently under development.
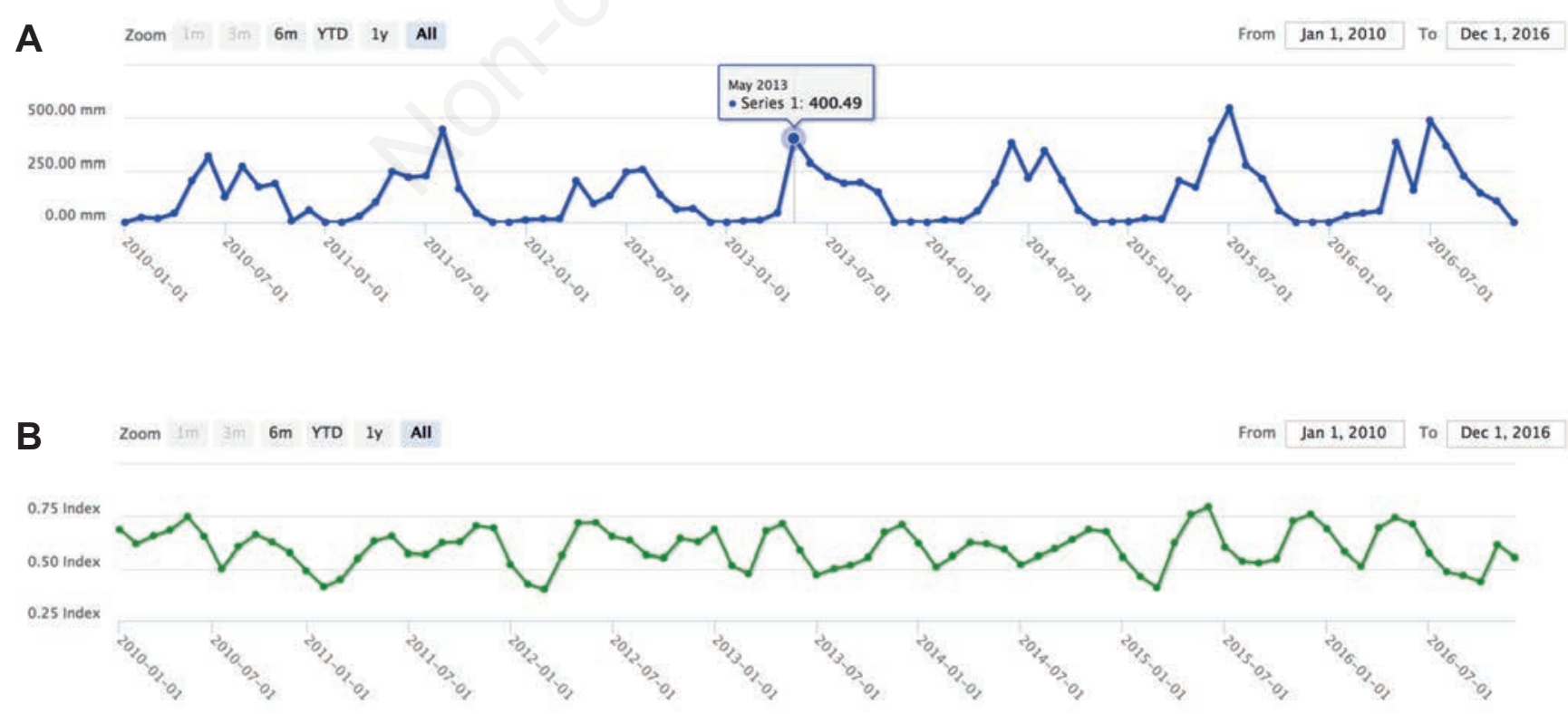

Figure 4. Examples of point search results. (A) Rainfall around Dhaka, Bangladesh (N 23.823, E 90.414); (B) Normalized Difference Vegetation Index for cropland around Kisum, Kenya (S 0.122, E 34.293). 


\section{Conclusions}

The information obtained from EOS covers the entire globe consistently and periodically. It spans a period of more than 30 years and is available in the form of archived data, even for areas such as developing countries for which in-situ data are sparse. Well-constructed, spatio-temporal environmental information, such as rainfall, LST, AOT and NDVI retrieved from satellites, is useful for the characterization of environmental factors in epidemiological studies. JPMAP is a user-friendly environmental information system publicly available via the Internet. This system collects, stores and integrates various satellite-derived environmental information related to epidemiological data and pre-processes the data to improve its accessibility for epidemiological research. JPMAP users need not be familiar with, or trained in, satellite data processing. JPMAP enables users to search the information desired with a simple GUI and utilize downloaded data without any additional image processing.

\section{References}

Altizer S, Ostfeld RS, Johnson PTJ, Kutz S, Harvell CD, 2013. Climate change and infectious diseases: from evidence to a predictive framework. Science 341:514-9.

Beck LR, Lobitz BM, Wood BL, 2000. Remote sensing and human health: new sensors and new opportunities. Emerg Infect Dis 6:217-27.

Bessho K, Date K, Hayashi M, Ikeda A, Imai T, Inoue H, Kumagai Y, Miyakawa T, Murata H, Ohno T, Okuyama A, Oyama R, Ssasaki Y, Shimazu Y, Shimoji K, Sumida Y, Suzuki M, Taniguchi H, Tsuchiyama H, Uesawa D, Yokota H, Yoshida R, 2016. An introduction to Himawari-8/9 Japan's new-generation geostationary meteorological satellites. J Meteorol Soc Japan 94:151-83.

Bontemps S, Defourny P, Bogaert EV, Arino O, Kalogirou V, Perez JR, 2011. GLOBCOVER 2009 Products Description and Validation Report. Available from: http://due.esrin.esa.int/ page_globcover.php

Bowles DC, Butler CD, Friel S, 2013. Climate change and health in Earth's future. Earth's Future 2:60-7.

Ceglar A, Toreti A, Balsamo G, Kobayashi S, 2017. Precipitation over Monsoon Asia: A comparison of reanalyses and observations. J Climate 30:465-76.

Colston JM, Ahmed T, Mahopo C, Kang G, Kosek M, Sousa Junior F, Shrestha PS, Svensen E, Turab A, Zaitchik B, 2018. Evaluating meteorological data from weather stations, and from satellites and global models for a multi-site epidemiological study. Environ Res 165:91-109.

Fujii H, Koike T, Imaoka K, 2009. Improvement of the AMSR-E algorithm for soil moisture estimation by introducing a fractional vegetation coverage dataset derived from MODIS data. J Remote Sens Society Japan 29:282-92.

Fukuda S, Nakajima T, Takenaka H, Higurashi A, Kikuchi N, Nakajima TY, Ishida H, 2013. New approaches to removing cloud shadows and evaluating the $380 \mathrm{~nm}$ surface reflectance for improved aerosol optical thickness retrievals from the GOSAT/TANSO-Cloud and Aerosol Imager. J Geophys Res Atmos 118:13520-31.

Frouin R, Murakami H, 2007. Estimating photosynthetically avail- able radiation at the ocean surface from ADEOS-II global imager data. J Oceanogr 63:493-503.

Gebreslasie MT, 2015. A review of spatial technologies with applications for malaria transmission modelling and control in Africa. Geospat Health 10:239-47.

Global Administrative Areas database (GADM, version 3.6), 2018. Available from: https://gadm.org

Hasan MA, Mouw C, Jutla A, Akanda AS, 2017. Quantification of rotavirus diarrheal risk due to hydroclimatic extremes over South Asia: Prospects of satellite-based observations in detecting outbreaks. GeoHealth 2:70-86.

Igarashi T, Kuze A, Sobue S, Yamamoto A, Yamamoto K, Oyoshi K, Imaoka K, Fukuda T, 2014. Japan's efforts to promote global health using satellite remote sensing data from the Japan Aerospace Exploration Agency for prediction of infectious diseases and air quality. Geospat Health 8:S603-S10.

Japan Aerospace Exploration Agency (JAXA), 2007. Global Satellite Mapping of Precipitation (GSMaP). Available from: https://sharaku.eorc.jaxa.jp/GSMaP/index.htm

Japan Aerospace Exploration Agency (JAXA), 2013. JAXA Satellite Monitoring for Environmental Studies (JASMES). Available from: http://www.eorc.jaxa.jp/JASMES/index map.html

Japan Aerospace Exploration Agency (JAXA), 2015. Advanced Land Observing Satellite World 3D-30 m (ALOS AW3D30). Available from: http://www.eorc.jaxa.jp/ALOS/en/aw3d30/ index.htm

Japan Aerospace Exploration Agency (JAXA), 2017. Global Change Observation Mission-Climate (GCOM-C). Available from: https://suzaku.eorc.jaxa.jp/GCOM_C/index.html

Japan Aerospace Exploration Agency (JAXA), 2018. JAXA's Public-health Monitor and Analysis Platform (JPMAP). Available from: http://www.jpmap-jaxa.jp/index_en.html

Kubota T, Shige S, Hashizume H, Aonashi K, Takahashi N, Seto S, Hirose M, Takayabu YN, Nakagawa K, Iwanami K, Ushio T, Kachi M, Okamoto K, 2007. Global precipitation map using satellite borne microwave radiometers by the GSMaP project: Production and validation. IEEE Trans Geosci Remote Sens 45:2259- 75 .

Laaidi K, Zeghnoun A, Dousset B, Bretin P, Vandentorren S, Giraudet E, Beaudeau P, 2012. The impact of heat islands on mortality in Paris during the August 2003 heat wave. Environ Health Perspect 120:254-59.

Lebov J, Grieger J, Womack D, Zaccaro D, Whitehead N, Kowalcyk B, MacDonald PDM, 2017. A framework for One Health research. One Health 3:44-50.

Li H, Sun D, Yu Y, Wang H, Liu Y, Liu Q, Du Y, Wang H, Cao B, 2014. Evaluation of the VIIRS and MODIS LST products in an arid area of Northwest China. Remote Sens Environ 142:11121.

Okamura Y, Hashiguchi T, Urabe T, Tanaka K, Yoshida J, Sakashita T, Amano T, 2018. Pre-launch Characterization and In-orbit Calibration of GCOM-C/SGLI. IEEE International Geoscience and Remote Sensing Symposium, July 2018, Valencia, Spain. pp 6651-6654.

Oliveira G, Brunsell NA, Moraes EC, Bertani G, Santos TVD, Shimabukuro YE, Aragão LE OC, 2016. Use of MODIS sensor images combined with reanalysis products to retrieve net radiation in Amazonia. Sensors 16:956.

Saigusa N, Ichii K, Murakami H, Hirata R, Asanuma J, Den H, Han SJ, Ide R, Li SG, Ohta T, Sasai T, Wang SQ, Yu GR, 2010. 
Impact of meteorological anomalies in the 2003 summer on Gross Primary Productivity in East Asia. Biogeoscience 7:64155.

Sakai T, Iizumi T, Okada M, Nishimori M, Grünwald T, Prueger J, Cescatti A, Korres W, Schmidt M, Carrara A, Loubet B, Ceschia E, 2015. Varying applicability of four different satellite-derived soil moisture products to global gridded crop model evaluation. Int J Appl Earth Obs Geoinf 48:51-60.

Smith KR, Woodward A, Campbell-Lendrum D, Chadee DD, Honda Y, Liu Q, Olwoch JM, Revich B, Sauerborn R, 2014. Human health: impacts, adaptation, and co-benefits. In: Field CB, Barros VR, Dokken DJ, Mach KJ, Mastrandrea MD, Bilir TE, Chatterjee M, Ebi KL, Estrada YO, Genova RC, Girma B, Kissel ES, Levy AN, MacCracken S, Mastrandrea PR, White LL, eds. Climate Change 2014: Impacts, Adaptation, and Vulnerability. Part A: Global and Sectoral Aspects. Contribution of Working Group II to the Fifth Assessment Report of the Intergovernmental Panel on Climate Change.
Cambridge University Press, Cambridge, USA, pp 709-754.

Tadono T, Ishida H, Oda F, Naito S, Minakawa K, Iwamoto H, 2014. Precise global DEM generation by ALOS PRISM. ISPRS Annals 2:71-6.

Takane M, Yabe S, Tateshita Y, Kobayashi Y, Hino A, Isono K, Okayasu H, Diop OM, Tadono T, 2016. Satellite imagery technology in public health: analysis of site catchment areas for assessment of poliovirus circulation in Nigeria and Niger. Geospat Health 11:355-61.

Tucker CJ, 1979. Red and photographic infrared linear combinations for monitoring vegetation. Remote Sens Environ 8:12750 .

United Nations, 2018. Sustainable Development Goals. Available from: https://sustainabledevelopment.un.org/?menu=1300

Wan Z, 2014. New refinements and validation of the collection-6 MODIS land-surface temperature/emissivity product. Remote Sens Environ 140:36-45. 